\title{
Effect of UV Radiation on Degradation of Durian Skin Fibre Composite
}

\author{
Siti Munirah Salimah Abd Rashid, Hazleen Anuar, Siti Nur E'zzati Mohd Apandi and Yose \\ Fachmi Buys
}

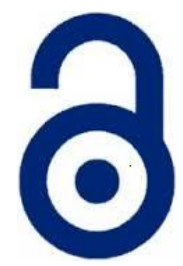

Received: 30 April 2018

Accepted: 22 May 2018

Published: 30 June 2018

Publisher: Deer Hill Publications

(c) 2018 The Author(s)

Creative Commons: CC BY 4.0

\begin{abstract}
Durian skin fibre (DSF) reinforced high-density polyethylene (HDPE) composite was fabricated by melt-blending and then compression moulded. As DSF is polar and hydrophilic in nature, while HDPE is non-polar and hydrophobic, thus the adhesion between them is low. Therefore, maleic anhydride-grafted-polyethylene (MAPE) was added to enhance the interaction of HDPE and DSF. This paper highlight the effect of MAPE on HDPE/DSF composite. DSF content from 10, 20, 30 and $40 \mathrm{wt} \%$ were immersed in water for 70 days. Water absorption was increased with DSF loadings. However, the increasing of water absorption was low as MAPE was added. Furthermore, tensile properties of HDPE/DSF composite was degraded after 500, 1000 and $2000 \mathrm{~h}$ of UV radiation exposure. Morphological observation under SEM showed that the fibre and matrix became less interacted after exposed to UV radiation. Voids and gaps between HDPE and DSF in the presence of MAPE were reduced as revealed under SEM micrographs. The colour index of the HDPE/DSF composite was increased and became whiter with UV radiation exposure but the presence of MAPE reduced the colour changed. This showed that MAPE significantly improved the properties of HDPE/DSF composite.
\end{abstract}

Keywords. Durian skin fibre, High-density polyethylene, Coupling agent, Water absorption, UV radiation

\section{INTRODUCTION}

In recent years, the use of natural fibre as reinforcement for plastics, replacing glass fibre and other synthetic material has increased rapidly. This is due to the low cost, good specific properties, low density, renewability, environmental friendliness and reduced energy consumption. One of the example of natural fibre is durian skin fibre (DSF) that extracted from durian or Durio zibethinus. Durian is popular in Southeast Asia like Thailand, Malaysia, Indonesia and Philippines. The statistical data from Malaysia Ministry of Agricultural and Agro-Based Industry reported that Malaysia produced 320,164 metric ton (MT) of durian fruit in 2013. This production was roughly 20,000 MT greater compared to 2012 [1]. As the production of durian increased, the agricultural waste of durian also increased and may lead to the environmental problems if this waste is not dispose efficiently. To reduce this problem, these agricultural waste can be recycled and reused to produce new product. Durian skin fibre consist of $47.2 \%$ cellulose, $9.63 \%$ hemicellulose, lignin and ash with $9.89 \%$ and $4.20 \%$ respectively [2,3]. Basically, cellulose has lower water absorption resistance because of the hygroscopic characteristic. Durian contains only $50-65 \%$ of flesh while the rest is considered as waste which include skin and seed which is $45-55 \%$ [1].

Composite based on thermoplastic reinforced with natural fibre was increased over the last decade. The improvement of using this composite is due to good performance of natural fibre, for instance low density, high stiffness, low cost, renewability, environmental friendly and low energy consumption compared to features of inorganic reinforcement like glass, silica, clay and many more.

Material durability is a vital information to determine the effect of weathering in analysing the material life span for outdoor application. Material with good mechanical properties is not necessarily can endure the degrading elements of weather. Mechanical properties are reduced because of exposing to the ultraviolet (UV) radiation of sunlight, rain and humidity [4]. It is an important issue to understand the interfacial adhesion between polymer

S. M. S. Abd Rashid, H. Anuar 凶, S. N. E'zzati, and F.B. Yose

Department of Manufacturing and Materials Engineering

International Islamic University Malaysia

PO Box 10, 50728 Kuala Lumpur, Malaysia

'E-mail: sitimunirahsalimah@gmail.com, 2E-mail: hazleen@iium.edu.my

3E-mail: snezzatiapandi@gmail.com, 4E-mail: yose@iium.edu.my

Reference: Abd Rashid, S. M. S., Anuar, H., E'zzati, S. N., and Yose, F. B. (2018). Effect of UV Radiation on Degradation of Durian Skin Fibre Composites. International Journal of Engineering Materials and Manufacture, 3(2), 105-112. 
matrix and fibre reinforcement in composite. This is to ensure the composite product can be used in a longer time. Degradation of the interface of matrix and reinforcement resulting in decrease the performance of the composite for the stress transfer between these materials and reduce the mechanical properties [5]. This paper reported the effect of water absorption and UV exposure on mechanical and physical properties on HDPE/DSF composite. Maleic anhydride grafted polyethylene (MAPE) was added as a coupling agent for HDPE and DSF.

\section{METHODOLOGY}

Durian waste was obtained from the local market. Firstly, the inner skin was removed and then washed thoroughly to remove any dirt and dusk. After that, the skin was dried in an oven for $24 \mathrm{~h}$ at $60{ }^{\circ} \mathrm{C}$ after chopping and grinding process. The skin was then crushed to get smaller size and was sieved with a $250 \mu \mathrm{m}$ siever to get durian skin fibre as exhibited in Figure 1.

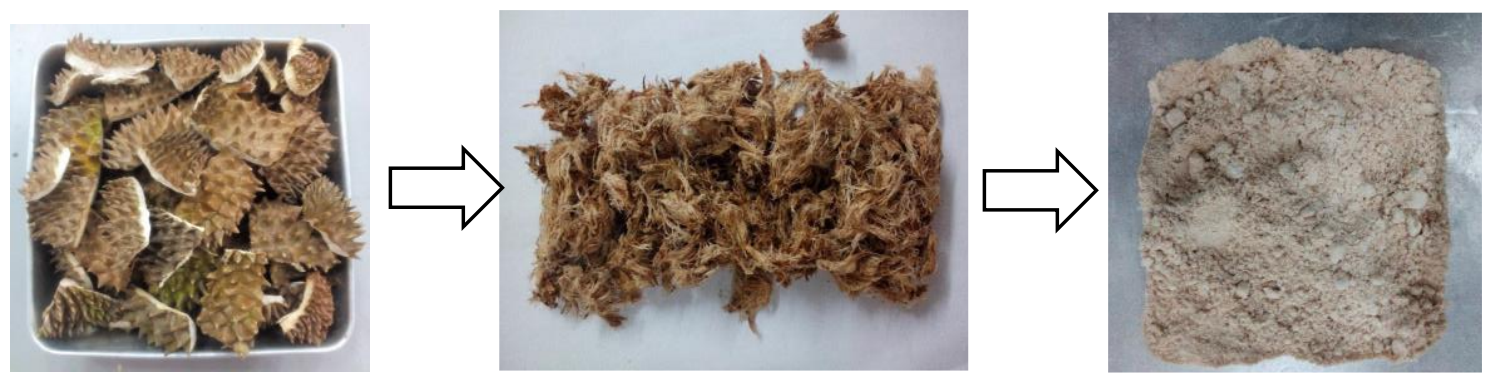

Figure 1: Preparation of durian skin fibre

The blending of HDPE/DSF composites were processed using Thermo Haake 600P internal mixer at temperature of $135^{\circ} \mathrm{C}$ and a rotational speed of $65 \mathrm{rpm}$ for $8 \mathrm{~min}$. The composition were varied from $10 \mathrm{wt} \%, 20 \mathrm{wt} \%, 30 \mathrm{wt} \%$ and $40 w t \%$ of DSF with the presence of $3 w t \%$ of MAPE. The other compositions are $10 w t \%, 20 w t \%, 30 w t \%$ and $40 \mathrm{wt} \%$ DSF with HDPE without MAPE and $100 \mathrm{wt} \%$ HDPE as well as shown in Table 1. Upon completion of the mixing process, the composites blend were shaped in the mould by using a hot press machine with a $135^{\circ} \mathrm{C}$ for 8 min in each bottom and upside.

The HDPE/DSF composite samples were placed in Q-Sun Xenon 1 (UTM Skudai, Johor) test chamber for UV exposure. The irradiation of UV was set to $1.10 \mathrm{~W} / \mathrm{m}^{2}$ and the black panel temperature was $65^{\circ} \mathrm{C}$. The samples were left in UV chamber for 500, 1000 and $2000 \mathrm{~h}$. All samples were then tested for tensile test, Fourier transform infrared (FTIR) spectroscopy and characterized for its morphology by scanning electron microscope (SEM). Lastly, the samples were also analysed for its colour to investigate the effect of degradation after exposed to UV radiation.

Table 1: Composition of the composite blend

\begin{tabular}{cccc}
\hline Sample & HDPE (\%) & DSF (\%) & MAPE (\%) \\
\hline 1 & 100 & - & - \\
2 & 90 & 10 & - \\
3 & 80 & 20 & - \\
4 & 70 & 30 & - \\
5 & 60 & 40 & - \\
6 & 87 & 10 & 3 \\
7 & 77 & 20 & 3 \\
8 & 67 & 30 & 3 \\
9 & 57 & 40 & 3 \\
\hline
\end{tabular}

\section{CHARACTERIZATION OF THE COMPOSITE}

Water absorption analysis was carried out to determine the amount of water absorbed into the sample. The weight of the composite was measured for every $24 \mathrm{~h}$ for the first two weeks and continued once a week until the increasing of weight is constant. Before weighing, the sample was wiped with a tissue paper to ensure it is dry. The percentage of water absorption (WA) is determined by following Eqn. 1.

$$
\mathrm{WA}(\%)=\left[\left(W_{1}-W_{0}\right) / W_{0}\right] \times 100
$$


where $W_{1}$ is the mass of the samples after immersion and $W_{0}$ is the mass of the samples before immersion

Tensile test was performed based on ASTM D638 using Universal Machine (Autograph ACS-X) with strain rate of $5 \mathrm{~mm} / \mathrm{min}$ and load of $5 \mathrm{kN}$. Scanning electron microscope (SEM) (JEOL, JSM-5600) was used to observe the fracture surface of the composite samples before and after the UV exposure with magnification of 500X. Before morphology was observed, the samples were cut into small pieces and coated with thin layer of gold to avoid electrostatic charging during evaluation. FTIR was conducted to obtain the information of the existence of the functional groups at the surface of the samples. FTIR spectra were analysed with an IR spectrometer within wave number range between $4000 \mathrm{~cm}^{-1}$ and $600 \mathrm{~cm}^{-1}$ using Perkin Elmer, Model Spectrum One. The optical properties was measured by UV-Visible Spectrometer with the CIELAB colour system. In this colour system, $L$ indicates lightness, $a$ and $b$ are the chromaticity coordinates where $a$ is the red/green coordinate and $b$ is the yellow/blue coordinate. Deltas for $L(\Delta L), a(\Delta a)$ and $b$ $(\Delta b)$ representing the differences between initial values (before weathering) and final values (after weathering) of $L$, $a$ and $b$, respectively. An increasing of $L$ value indicates the sample is lightening. For example, positive $\Delta L$ for lightening and negative $\Delta L$ for darkening. Positive $\Delta a$ mean it switch toward red while negative $\Delta a$ mean it switch toward green. Positive $\Delta b$ signifies a shift toward yellow and negative $\Delta b$ signifies a shift toward blue. The total colour difference $(\Delta E)$ is always positive and determined by using Eqn. 2.

$$
\Delta E=\left(\Delta L^{2}+\Delta a^{2}+\Delta b^{2}\right)^{1 / 2}
$$

\section{RESULTS AND DISCUSSION}

\subsection{Water Absorption Test}

Figure 2 showed the percentage of water absorption of HDPE/DSF composites with and without MAPE. Water absorption of the composite samples were higher as the composition of DSF was increased. The water absorption of $40 \mathrm{wt} \%$ DSF was increased rapidly in the first ten days and continue until they reached the maximum and constant water uptake. The weight of the composite samples remain constant at certain time. At this point, it is called saturation point and the duration of this point is different for all compositions. Composition with $40 \mathrm{wt} \%$ of DSF without MAPE had the highest water uptake due to the hydrophilic nature of natural fibre and poor interfacial interaction between HDPE and DSF. DSF is a natural fibre and it is hydrophilic thus easy to absorb the moisture. The composition with $10 \mathrm{wt} \%$ of DSF with MAPE had better interaction between DSF and HDPE.

The percentage of water absorbed was depend on the content of natural fibre in which $10 \mathrm{wt} \%$ was the lowest, then $20 \mathrm{wt} \%$ followed by $30 \mathrm{wt} \%$ and $40 \mathrm{wt} \%$, respectively. This means that with increasing of DSF content, the cellulose content and the number of hydroxyl $(\mathrm{OH})$ group in the composites also increased. This will result in increasing the water uptake as free $\mathrm{OH}$ - groups come in contact with water and form hydrogen bonding. The composite with lower cellulose content reach the equilibrium moisture content more quickly [6,7]. However, adding MAPE into HDPE/DSF composite reduced the water absorption in the composite as shown in Figure 2.

Each composition of DSF with MAPE absorbed lower moisture compared to without MAPE. MAPE acted as a coupling agent and thus blocked the permeation of water into the durian skin fibre. Water absorption of $10 \mathrm{wt} \%$ DSF with MAPE at 70 days was $2.3 \%$ higher compared to $10 \mathrm{wt} \%$ DSF without MAPE. This indicated that MAPE helped in improving the interfacial adhesion between DSF and HDPE by reducing the gaps as observed under SEM micrograph in Figure 4. For pure HDPE, it showed that the water absorption was constant as it hydrophobic and absorbed no moisture.
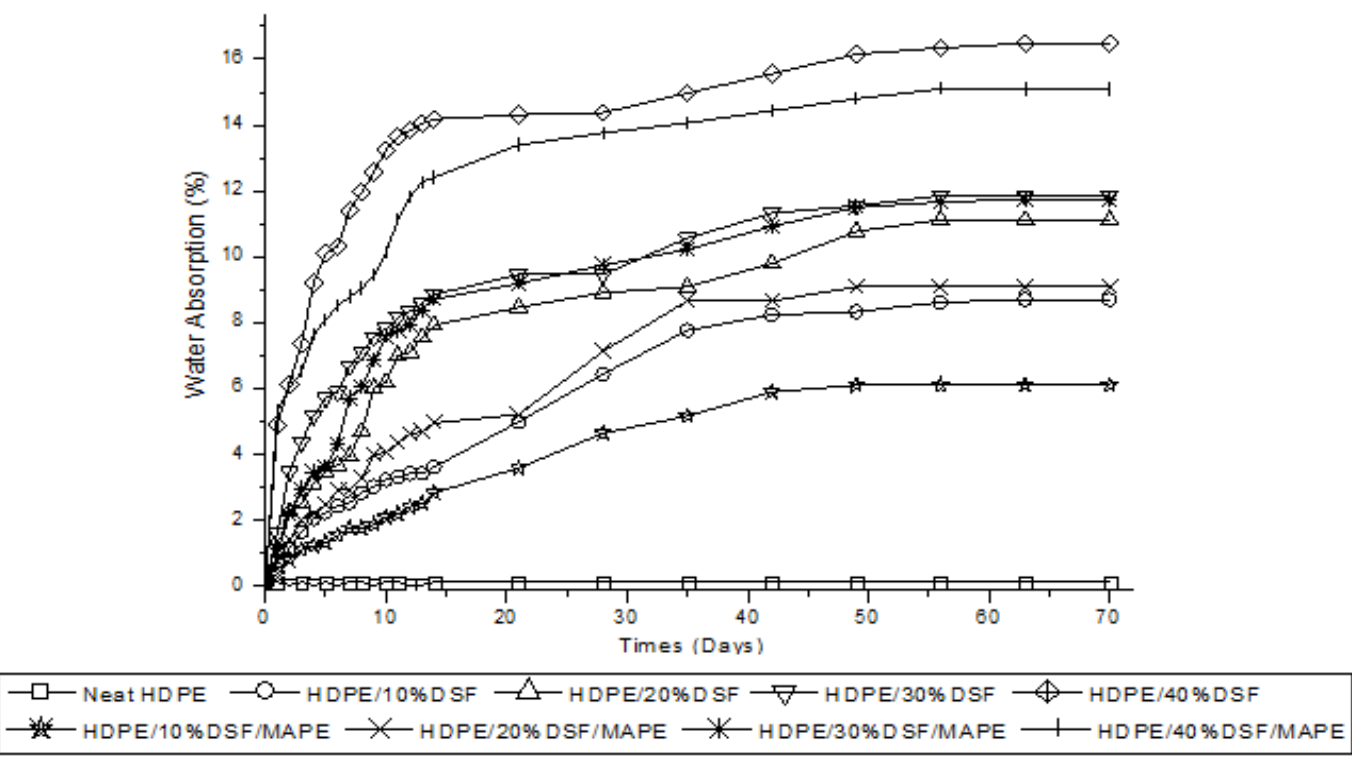

Figure 2: Percentage of water absorption of unreinforced HDPE, HDPE/DSF and HDPE/DSF/MAPE composite 


\subsection{Tensile Test}

Figure 3 exhibited the tensile strength of unreinforced HDPE and HDPE/DSF composite with and without MAPE. HDPE/DSF composite with MAPE had higher tensile strength compared to without MAPE but lower than unreinforced HDPE. From Figure 3, it was observed that the tensile strength was decreased as the exposure time to the UV was longer for all specimens. Tensile strength of the unexposed specimens were highest for each sample followed by 500,1000 and $2000 \mathrm{~h}$, respectively. The tensile strength of $500 \mathrm{~h}$ exposure time for HDPE recorded 15.2 MPa which was $11.6 \%$ higher compared to $1000 \mathrm{~h}$. Tensile strength of HDPE/DSF dropped significantly at $38.9 \%$ after $1000 \mathrm{~h}$ of exposure. This was due to the broken polymer chains by UV radiation into smaller and micro-cracking occurred in polymer leading to the failure of specimens under lower loading with exposure time. Similar observation was also reported by Umar et al. (2012) on effect of accelerated weathering on tensile properties of kenaf reinforced high density polyethylene composites [4].

The tensile strength of DSF composite was higher in the presence of MAPE because the interaction between filler and matrix became stronger [8,9]. Interfacial adhesion was degraded and pore size was increased as the specimens were exposed to UV radiation. The UV exposure encouraged the molecular chain scission and formation of carbonyl and hydroperoxides. The poor interfacial bonding between fibre and polymer resulted in lower tensile strength. However, the addition of MAPE enhanced the strength of composite by bridging the DSF and HDPE and made their interaction better. This is evident in Figure 3 where the tensile strength of DSF composites with MAPE were higher compared to without MAPE. The existing of voids might also be a factor for the drop in tensile strength of HDPE/DSF composites.

\subsection{SEM Micrograph}

SEM micrographs of the fracture surface from the tensile test of HDPE/DSF and HDPE/DSF/MAPE composites of unexposed and exposed to UV radiation were shown in Figure 4. In Figure 4(a), the fibre seem to detach from HDPE matrix and the formation of voids were clearly seen. This was due to the poor interfacial adhesion between the fibre and matrix. These features showed that the tensile strength of HDPE/DSF composite was low in the absence of MAPE. The presence of voids or gaps led to more weakening point, thus it diminished the strength [10]. The efficiency of stress transfer from matrix to fibre was also reduced because of the incompatibility between HDPE and DSF. Therefore, MAPE was used as a bridge between HDPE and DSF. The presence of MAPE enhanced the interfacial adhesion between matrix and fibre and hence improved the tensile strength of the composite. In addition, the voids between HDPE and DSF were decreased as shown in Figure 4(b). As a result, the stress transfer between matrix and fibre could be effective.

However, the surface characteristic of HDPE/DSF composites were changed significantly after exposure to UV radiation. The bonding between the matrix and fibre became poorer for both specimens with and without MAPE. From Figure 4(c), it revealed the surface of fibre was unequally distributed in the matrix due to the presence of voids. These voids leading to brittle and low tensile strength. Nevertheless, the crack formation in the HDPE matrix appeared to be less severe for the HDPE/DSF composite with MAPE compared to without MAPE. Furthermore, the presence of more voids were shown in Figure 4(c) as coupling agent was absent compared to Figure 4(d). A good compatibility between the matrix and fibre improved the strength after HDPE/DSF composites were treated with MAPE.

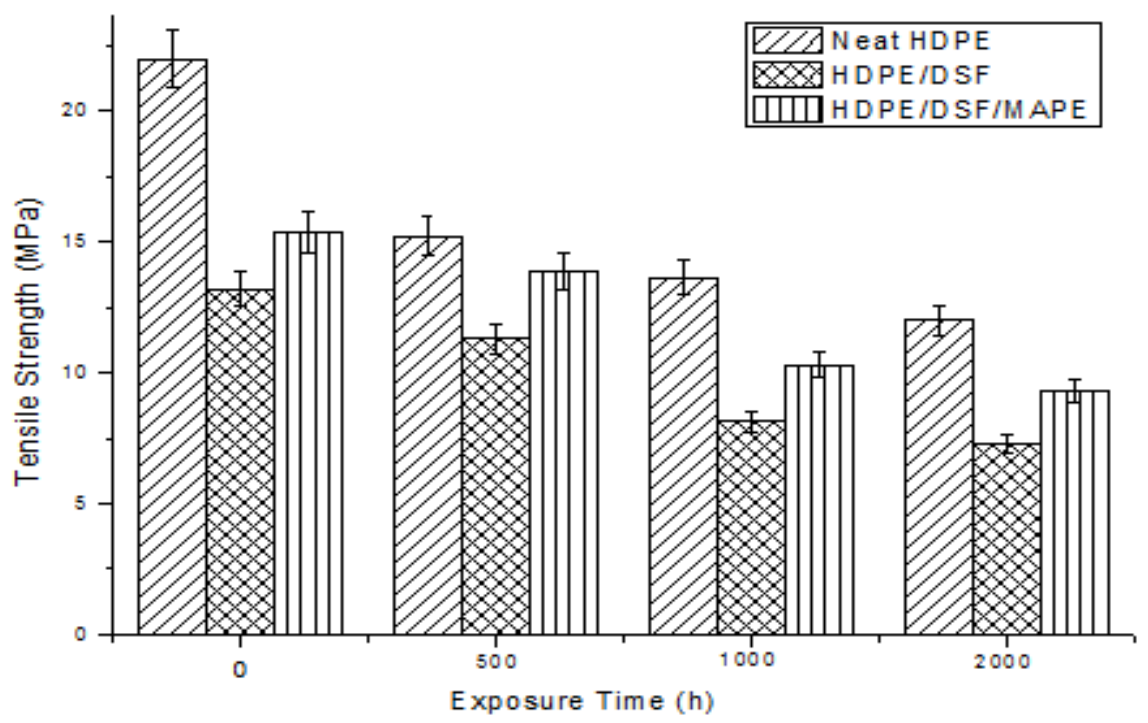

Figure 3: Effect of exposure time of tensile strength of unreinforced HDPE, HDPE/DSF and HDPE/DSF/MAPE composite 

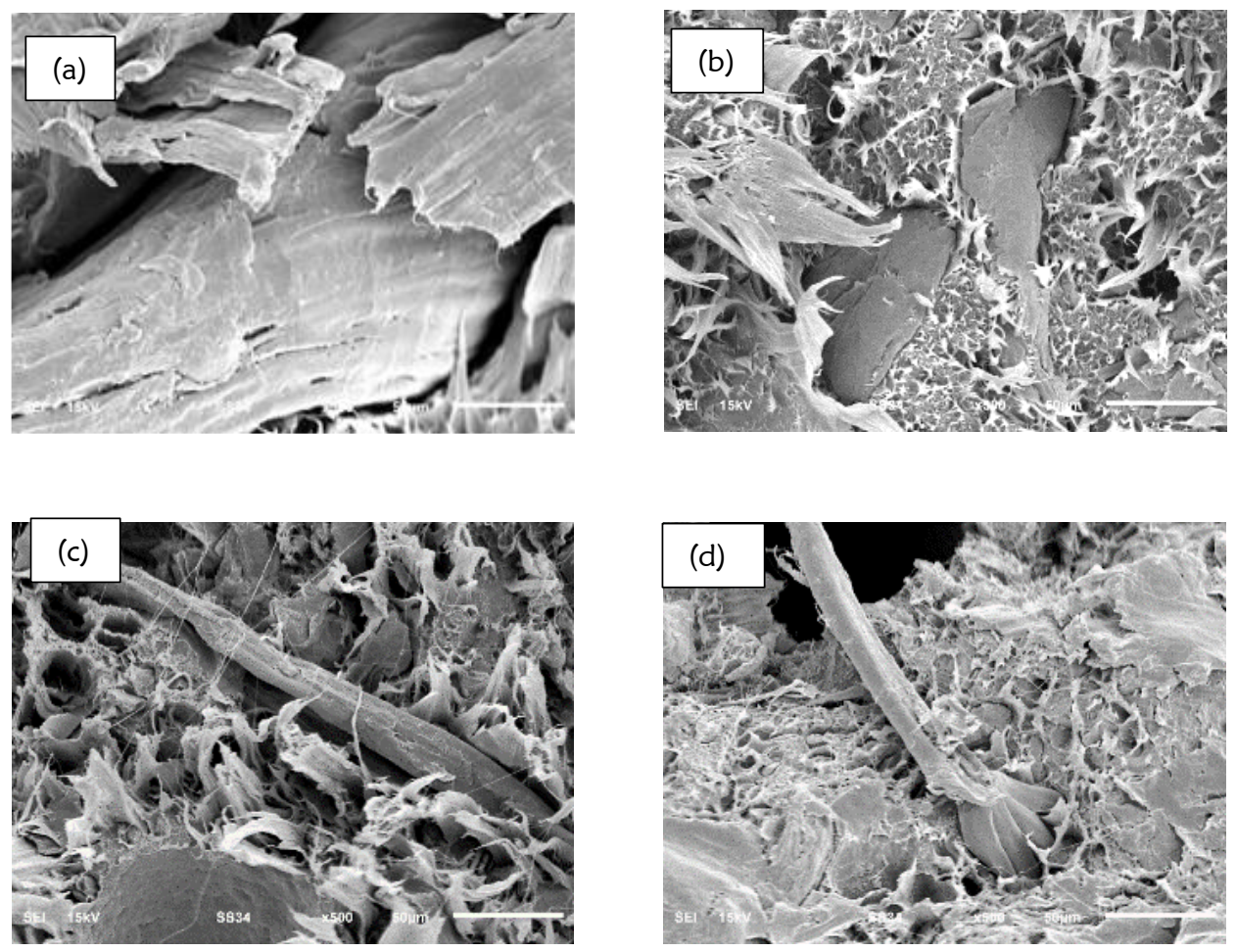

Figure 4: SEM micrographs for unexposed UV of HDPE/DSF composite (a) without MAPE, (b) with MAPE, and UV exposure (c) without MAPE, (d) with MAPE

\subsection{Fourier Transform Infrared Analysis}

The infrared spectra for durian fibre was obtained by using an FTIR spectrometer as shown in Figure 5 . From the Figure 5(a), the peaks at 2915-2914 cm-1 and $2847 \mathrm{~cm}-1$ represent the $\mathrm{C}-\mathrm{H}$ stretching vibration while the peaks at $1472 \mathrm{~cm}-1$ and 1462-1461 cm-1 demonstrate the $\mathrm{C}-\mathrm{H}$ bending from the alkane group [13]. The OH peak was more likely to be broader in the presence of MAPE from $3500-3000 \mathrm{~cm}-1$ showing that a reaction took place between the fibre's hydroxyl group and polar group in MAPE because of esterification reaction supplied by the MAPE [14]. The peak between 1750-1650 cm-1 is related with the $C=O$ group and owned by maleic anhydride in MAPE. MAPE produced esterification reactions and covalent bonding with the hydroxyl group in cellulose fibre in order to enhance the bonding between HDPE matrix and DSF [14].

The bands between 1461-730 cm-1 was disappeared after exposed to UV radiation. The peak at $802 \mathrm{~cm}-1$ shown in Figure 5(b) could be result from presence of lignin and was removed after exposed to UV. It was also noticed that the peak at $1262 \mathrm{~cm}-1$ was missing as illustrated in Figure 5(b). This is due to the hemicellulose that bind to each other was removed. The peaks detected at 1472-1464 cm-1 and 730-718 cm-1 associated with content of polyethylene crystalline (1472 and $730 \mathrm{~cm}-1)$ and amorphous content $(1464-718 \mathrm{~cm}-1)$ [13,15].

\subsection{Optical Test}

The colour of composite specimens was changed as it underwent the photodegradation process. Figure 6 revealed the lightness of specimens was increased after it exposed to UV radiation. This showed that the specimens became whiter as exposure times was longer from 500 to $2000 \mathrm{~h}$. However, the L values for HDPE/DSF/MAPE composite was lower than HDPE/DSF composite. The lightening of composite was lower due to the presence of coupling agent. The addition of MAPE blocked the penetration of UV radiation and to mask the bleaching of HDPE/DSF [11].

The values of $\triangle \mathrm{E}$ at different exposure times for HDPE/DSF with and without MAPE were revealed in Table 2. The increased values proved the increased of lightness as specimens turned whiter after it exposed to UV radiation. The specimens with $500 \mathrm{~h}$ of exposure times showed the lowest colour shift followed by 1000 and $2000 \mathrm{~h}$, respectively. The difference of $\Delta \mathrm{E}$ was due to bleaching of the fibre component, degradation of polymer as it exposed to UV radiation and the darkening effect which could be linked to surface oxidation [12]. Exposure to UV radiation, moisture and oxidation of polymer degraded the surface layer of composite and removed the colour of materials. Therefore, the colour of composite was changed. 


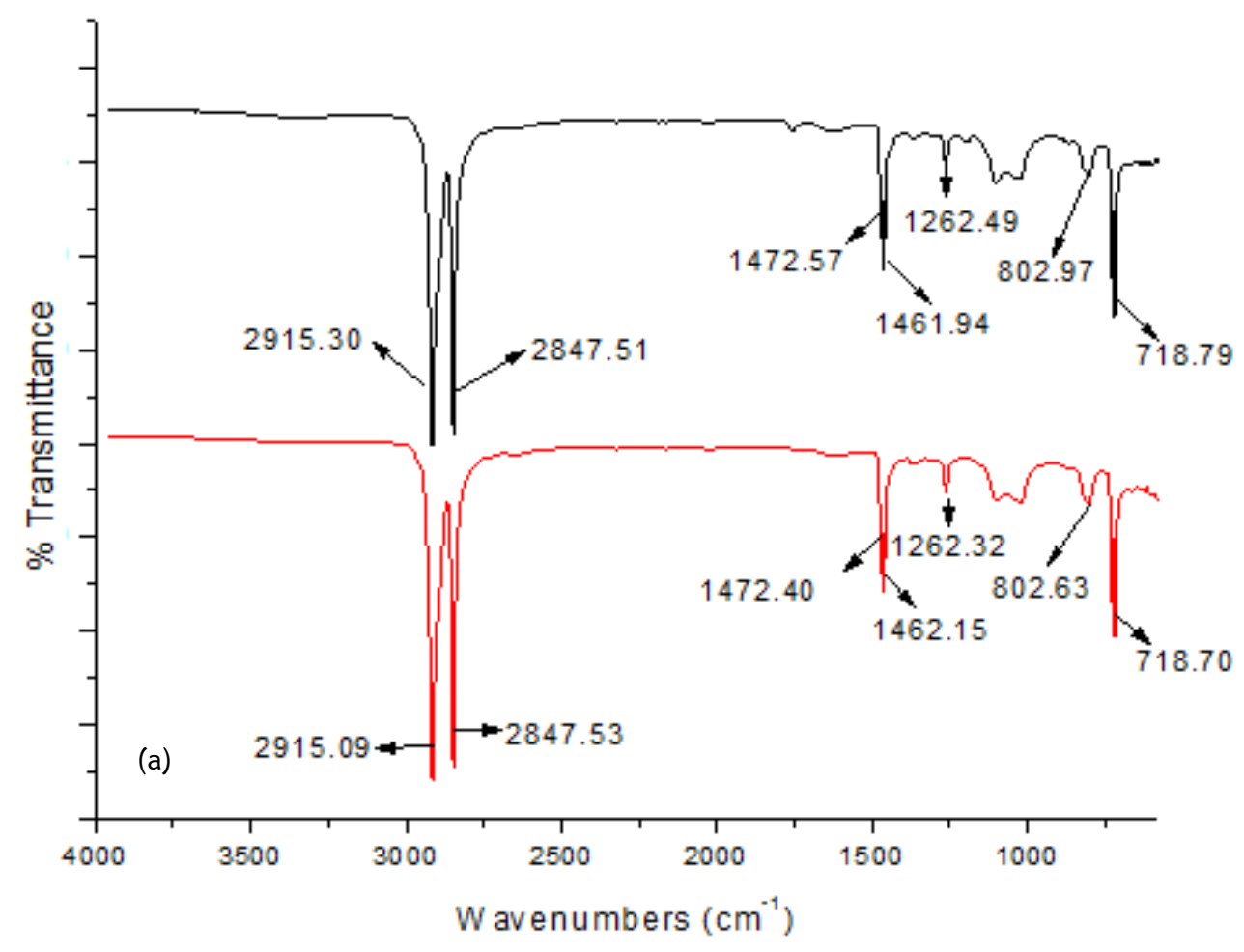

-HDPE/DSF —HDPE/DSF/M APE

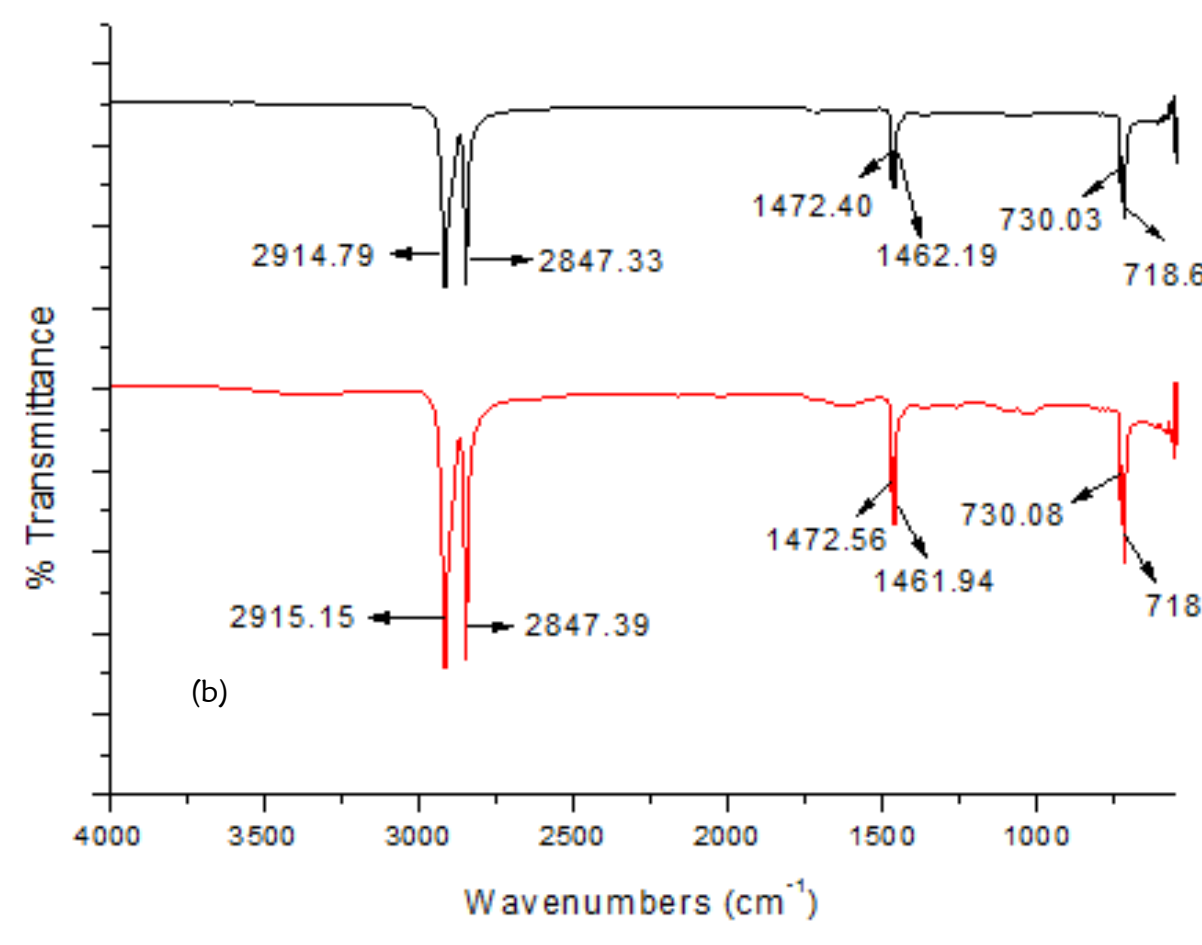

HDPE/DSF - HDPE/DSF/M APE

Figure 5: IR spectra of HDPE/DSF composite and HDPE/DSF/MAPE composite (a) unexposed UV (b) exposed UV 


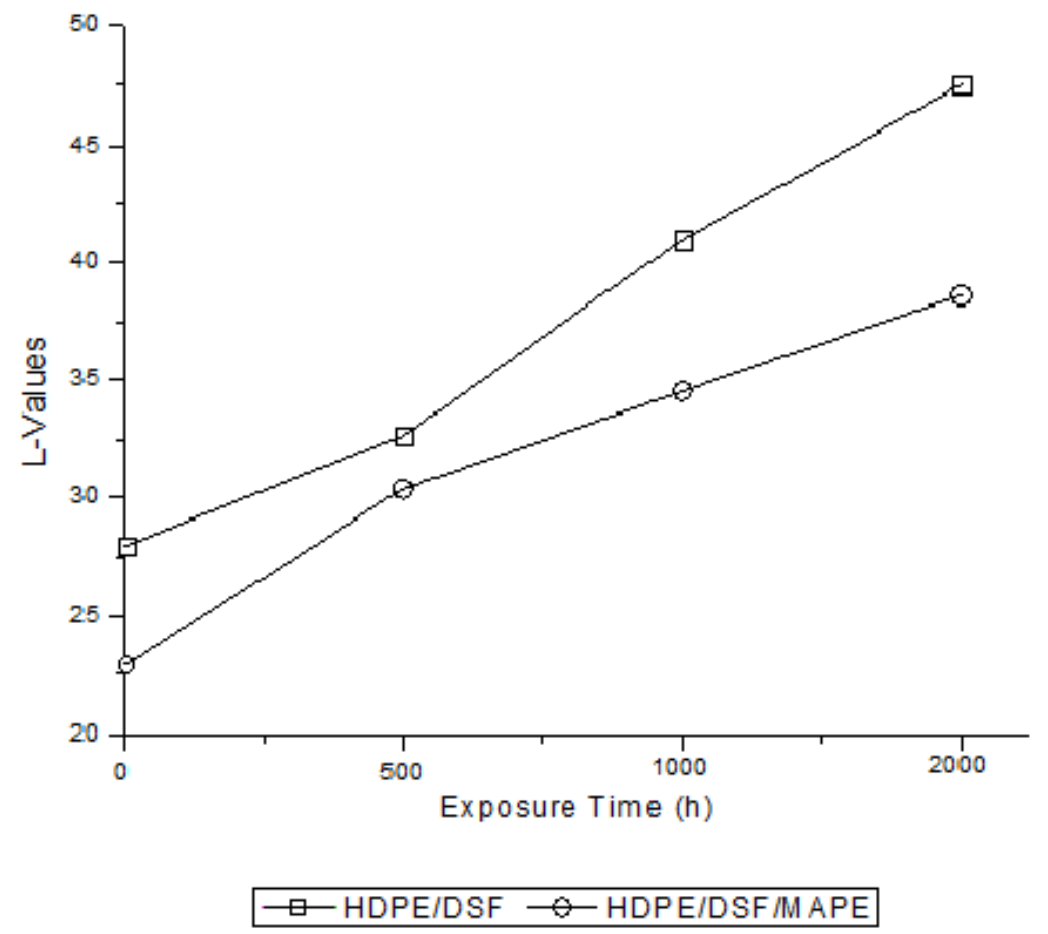

Figure 6: Effect of exposure time on L of HDPE/DSF and HDPE/DSF/MAOE

Table 2: $\Delta E$ at various exposure time

\begin{tabular}{lcc}
\hline \multirow{2}{*}{ Exposure Time $(\mathrm{h})$} & \multicolumn{2}{c}{ Colour Change $(\Delta E)$} \\
\cline { 2 - 3 } & HDPE/DSF & HDPE/DSF/MAPE \\
\hline 500 & 9.04 & 9.44 \\
1000 & 14.82 & 13.46 \\
2000 & 20.07 & 16.27 \\
\hline
\end{tabular}

\section{CONCLUSIONS}

In this research, durian skin fibre (DSF) reinforced high density polyethylene (HDPE) with and without maleic anhydride-grafted-polyethylene (MAPE) as a coupling agent has been developed. The effects of MAPE on water absorption, tensile test, surface morphology and colour properties showed the followings:

1. The addition of MAPE reduced the water uptake. This suggests that coupling agent enhanced the interaction between natural fibre and polymer matrix as it decreased the water absorption when MAPE was added.

2. The performance of HDPE/DSF composite was degraded as the time exposure to UV radiation increased to 500,1000 and $2000 \mathrm{~h}$. However, incorporation of MAPE reduced the degradation of the HDPE/DSF composite. For example, after $2000 \mathrm{~h}$ of exposure, the tensile strength of HDPE/DSF without MAPE was 7.3 MPa and increased to 9.3 MPa when MAPE was added.

3. The surface morphology under SEM observation revealed that deterioration of the surface layer on HDPE/DSF composite occurred after exposed to UV radiation. Interfacial adhesion between HDPE and DSF for both unexposed and exposed UV radiation were poorer in the absence of MAPE.

4. The existence of MAPE reduced the colour change of HDPE/DSF composite.

\section{ACKNOWLEDGEMENT}

The authors wish to thank Fundamental Research Grant Scheme (FRGS16-003-0502) and Fundamental Research Grant Scheme (FRCS14-108-0349) awarded by the Ministry of Education Malaysia for the financial support and International Islamic University Malaysia for the facilities and equipment in making these studies a success. 


\section{REFERENCES}

1. Manshor, M. R., Anuar, H., Mohd Nasir, N. A., Ahmad Fitrie, M. I., Wan Busu, W. N., El-Shekeil, Y. A., \& Wahit, M. U. (2014). Mechanical, thermal and morphological properties of durian skin fibre reinforced pla biocomposites. Materials and Design, 59, 279-286.

2. Charoenvai, S. (2014). A new material from recycled HDPE and durian peel fiber. The 5th TSME International Conference on Mechanical Engineering. Chiang Mai: TSME-ICOME Asean and Beyond.

3. Charoenvai, S. (2014). Durian peels fiber and recycled HDPE composites obtained by extrusion. Energy Procedia, $56,539-546$.

4. Umar, A., Zainudin, E., \& Sapuan, S. (2012). Effect of accelerated weathering on tensile properties of kenaf reinforced high-density polyethylene composites. Mechanical Engineering and Sciences (JMES), 2, 198-205.

5. Rashdi, A., Sapuan, S., Ahmad, M., \& Khalina, A. (2010). Combined effects of water absorption due to water immersion, soil buried and natural weather on mechanical properties of kenaf fibre unsaturated polyester composites (KFUPC). Mechanical and Materials Engineering (IJMME), 5(1), 11-17.

6. Abd Aziz, N. Z., Mohamed, R., \& Fahimi, M. (2015). Effects of kenaf and rice husk on water absorption and flexural properties of kenaf /CaCO3/HDPE and rice husk/CaCO3/HDPE hybrid composites. International Journal of Environment, Chemical, Ecological, Geological and Geophysical Engineering, 9(4), 349-353.

7. Penjumras, P., Abdul Rahman, R., Talib, R., \& Abdan, K. (2015). Mechanical properties and water absorption behaviour of durian rind cellulose reinforced poly(lactic acid) biocomposites. Advanced Science Engineering Information Technology, 5(5), 343-348.

8. Makara, L., Rashid, A., Othman, N., Tezuka, Y., \& Chhorda, P. (2014). Comparison of mechanical properties and curing characteristics of natural rubber composites with different coupling agent. Advanced Materials Research, 858, 24-31.

9. Huang R., Xu X., Lee S., Zhang Y., Kim B.-J., \& Wu Q. (2013). High density polyethylene composites reinforced with hybrid inorganic fillers: morphology, mechanical and thermal expansion performance. Materials, 6, 4122 4138.

10. Anuar, H., Mohd Nasir, N. A, \& El-Shekeil, Y. (2015). Effects of coupling agent on the properties of durian skin fibre filled polypropylene composite. Chemical, Molecular, Nuclear, Materials and Metallurgical Engineering, 9(12), 1300-1304.

11. Stark, N., \& Matuana, L. (2003). Ultraviolet weathering of photostabilized wood-flour-filled high-density polyethylene composites. Applied Polymer Science, 90, 2609-2617.

12. Bajwa, D., Bajwa, S., \& Holt, G. (2015). Impact of biofibers and coupling agents on the weathering characteristics of composites. Polymer Degradation and Stability, 120, 212-219.

13. Stark, N., \& Matuana, L. (2004). Surface chemistry changes of weathered hdpe/wood-flour composites studied by XPS and FTIR spectroscopy. Polymer Degradation and Stability, 86, 1-9.

14. Zulkifli, N. I., Samat, N., Anuar, H., \& Zainuddin, N. (2015). Mechanical properties and failure modes of recycled polypropylene/microcrystalline cellulose composites. Materials and Design, 69, 114-123.

15. Stark, N., \& Matuana, L. (2004). Surface chemistry and mechanical property changes of wood-flour/high-densitypolyethylene composites after accelerated weathering. Applied Polymer Science, 94, 2263-2273. 